\title{
Cartografía de la violencia en la trilogía del desencanto de Alejandro Páez Varela*
}

\author{
Mónica Torres Torija González ${ }^{1}$ \\ Universidad Autónoma de Chihuahua (México)
}

\section{Resumen:}

El imaginario norteño de Alejandro Páez Varela en su trilogía del desencanto, Corazón de Kaláshnikov (2009), ${ }^{2}$ El reino de las moscas (2012) y Música para perros (2013) traza una cartografía narrativa que permite comprender los fenómenos sociales de la frontera norte donde la violencia y la inseguridad de Ciudad Juárez refleja los ambientes sórdidos y la lucha constante por la subsistencia. En este trabajo se pretende dilucidar los siguientes interrogantes: ¿cuál es el anclaje a esas realidades latentes que detonan el imaginario espacial?, ¿cuál es la identidad de estos espacios urbanos norteños, topotesia ${ }^{3}$ de una realidad nacional?, ¿cuáles son los avatares que aquejan a sus pobladores en un intento de subsistir en un mundo de violencia que

\begin{abstract}
The northern imaginary of Alejandro Páez Varela in his trilogy of disenchantment, Corazón de Kaláshnikov (2009), El reino de las moscas (2012) y Música para perros (2013) traces a narrative cartography that allows the reader to understand the social phenomena of the northern border where the violence and insecurity of Ciudad Juarez reflect the sordid environments and the constant struggle for subsistence. This work aims to elucidate the following questions: what is the anchor to these latent realities that trigger the spatial imaginary? What is the identity of these northern urban spaces, topothesia of a national reality? What are the vicissitudes that afflict its inhabitants in their attempt to survive in a world of violence that constantly threatens
\end{abstract}

\footnotetext{
* Cartography of violence in the trilogy of disenchantment, by Alejandro Páez Varela 1 Dra. en Filosofía con Acentuación en Estudios de la Cultura. Profesora de tiempo completo de la Universidad Autónoma de Chihuahua. Correo electrónico: mtorrestorija@hotmail.com

2 La edición con la que se trabajará en este artículo corresponde a la de Alfaguara con fecha de 2014.

3 La topotesia es una figura literaria que se utiliza para la descripción de los espacios literarios ficticios, en este sentido, lo utilizo para cartografiar el locus urbano de Ciudad Juárez, como espacio de frontera donde acontece la violencia que plasma Páez Varela y que constituye la esencia de las narrativas del dolor en la trilogía del desencanto. Lejos de ser un paisaje idílico, se convierte en un lugar distópico, en el locus de la violencia del espacio fronterizo en el norte de México.
} 
los amenaza constantemente y los orilla a desplazamientos de diferente índole?, ¿es posible repensar el norte como un espacio privilegiado de significación geopolítica que desborda los imaginarios del narco, la inmigración, el feminicidio y la precariedad de las ciudades y comunidades norteñas? y, por último, ¿cuáles son los mecanismos literarios utilizados para recrear una "narrativa del dolor"?

Palabras clave: Cartografía narrativa, espacio imaginario, topotesia, identidades, estética de la violencia. them and pulls them over to displacements of different kinds? Is it possible to rethink the North as a privileged space of geopolitical significance that overflows the imaginaries of the narco, immigration, the femicide and the precariousness of northern cities and communities? And finally, what are the literary mechanisms used to recreate a "narrative of pain"?

Keywords: Narrative cartography, imaginary space, topothesia, identities, aesthetics of violence.

En Ciudad Juárez hay mucha más valentía que perdición, muchísima más voluntad que perdición. Insisto, la valentía recae en las mujeres, las más estigmatizadas, las más violentadas. Ellas mantienen la ciudad unida. Eso es lo que mantiene viva a la ciudad.

Páez Varela (citado en Torres Torija, 2015)

El imaginario en la literatura del Norte de México ha construido una cartografía literaria que delinea una topotesia que proyecta las identidades soterradas y emergentes, producto de los desplazamientos que han caracterizado la sociedad actual. El espacio que configura la geografía norteña se ha caracterizado por ser una tierra inhóspita y bárbara desde sus primeros pobladores; una franja fronteriza que, en la historia de fines del siglo XX, protagonizó una de las más encarnecidas facetas de la violencia derivadas de las políticas del Estado mexicano por enfrentar al narcotráfico y que han hecho de Ciudad Juárez una de las ciudades de mayor peligrosidad no sólo en el país, sino en el mundo entero.

A raíz de la presencia del narcotráfico, de los feminicidios, la ola de secuestros, las extorsiones y la corrupción existente, no era de extrañarse que la literatura no se mantuviera ajena a estos acontecimientos y empezaran a manifestarse testimonios, crónicas y narrativas que plasmaran esta violencia. Hoy en día se habla mucho de narco literatura, pero en el caso que nos ocupa, considero que la trilogía del desencanto, de Alejandro Páez Varela, se ubica más dentro de lo que Magali Velasco (2013) ha referido como las "narrativas del dolor", ya que las historias que se relatan en ellas se ven afectadas indudable- 
mente por una situación caótica derivada de una problemática social donde el narcotráfico ha hecho mella en la vida de los habitantes de Ciudad Juárez y de la sierra chihuahuense. Pero el narcotráfico no es la figura protagónica de estas novelas. Es el contexto adverso, casi trágico, que arrastra a personajes cuyo anhelo principal es preservar su historia de amor. Páez Varela incluso ha manifestado:

\begin{abstract}
Nací en Ciudad Juárez, crecí allí y la ciudad marcó mucho de lo que soy. No hay manera de renunciar a lo que puedo narrar cuando lo que voy a narrar está contaminado de mí mismo o, dicho de otra manera, uno no escribe desde la nada uno escribe desde lo que es y yo crecí en ese ambiente Lo que está en mis libros es lo que me es natural, yo no tenía otra cosa respecto de la cual escribir. Yo digo que escribo historias de amor y, ya ven, me salen un montón de balazos (Santos, 2016, p. 307).
\end{abstract}

Alejandro Páez Varela proviene de una familia de periodistas y, como tal, ha ejercido esta profesión al ser director de contenidos de Sin embargo.mx, subdirector editorial de El Universal, de la revista Día Siete, editor de Reforma y editor de El Economista. Ha sido un testigo privilegiado de la violencia que azota su ciudad y su agudo sentido crítico y reflexivo ha estado manifiesto en sus primeras obras de periodismo narrativo en colaboración: Los Suspirantes (2005), Presidente en espera (2006), Los Amos de México (2007), Los Intocables (2007). Ha coordinado Indomables (2015) y La guerra por Juárez (2009) donde expresa:

participamos varios periodistas queridos de Chihuahua; denunciamos, sin pelos en los dedos, el terrible error del gobierno de Felipe Calderón al lanzar una guerra contra las drogas sin consultar con nadie, que destruyó mi querida ciudad, mi adolorida frontera, y volvió al país en un campo de batalla en el que miles y miles de mexicanos han brindado su vida por nada (Páez Varela, 2009).

Su incursión en el terreno literario inicia con Paracaídas que no abre (2008) y el reconocimiento vendrá con la publicación de Corazón de Kaláshnikov (2009), al que le seguirán No incluye baterías (2010), El reino de las moscas (2012), Música para perros (2013) y, su más reciente libro, Oriundo Laredo (2016).

Indudablemente, la violencia es la atmósfera que predomina en el ambiente y que somete a los habitantes a una lucha continua en el locus fronterizo. La fisonomía urbana se ha convertido en un lugar 
donde el mal acecha y donde el peligro ronda en cualquier lado. Paradójicamente, los personajes de la trilogía realizan itinerarios diversos en un vano intento por buscar un espacio que los acoja y los libere de una fatalidad que los persigue y a la cual es difícil eludir. La mayoría de ellos acaba en una muerte inexorable o en una vorágine de desgracias que los sume en una devastadora soledad:

\begin{abstract}
Las ciudades del norte se han convertido en un lugar sin ley donde todo estå permitido porque no hay poder que controle a los que tienen el poder. En un inicio, el infierno norteño solo aparecía por las noches, cuando las luces despertaban a las almas hambrientas del inframundo y salían a la calle los excesos, la ebriedad, la impunidad (De Orduña, 2017: 296).
\end{abstract}

\title{
¿Cuál es el anclaje a esas realidades latentes que detonan el imaginario espacial?
}

Alejandro Páez Varela utiliza una hibridez genérica para la construcción de la trilogía del desencanto. A partir del tono de las "narrativas del dolor", predominantemente melancólico y nostálgico, el autor fusiona el relato con lo que también se ha denominado la novela reportaje o la crónica. El mismo autor la ha señalado como una "novela de hechos, escritos under road o caminera" (Aguilar, 2009: 17). Tal efecto le confiere verosimilitud a lo narrado y le elimina lo que pudiera considerarse una nota roja. Los hechos referidos tienen fuertes anclajes en el locus fronterizo donde acontecen y la novela se nos presenta como una crónica urbana con estampas de varias escenas de sucesos que se van a ir entrelazando, como vasos comunicantes que hilvanan, al final de cuentas, varias historias de amor sacudidas por una fatalidad que imposibilita la supervivencia en un mundo agreste y convulso. Como lo ha expresado Magali Velasco (2013), esta variante narrativa ha proliferado como una necesidad esclarecedora de la verdad que, llevada a la literatura, se convierte en la estética de la violencia del norte de México (De Orduña, 2017).

El periodismo en Ciudad Juárez, sobre todo el ejercido en la última década del XX y lo que va del nuevo milenio ha privilegiado la crónica y el reportaje como géneros que recopilan las narrativas del dolor: el feminicidio, las desapariciones, los tejidos sociales fracturados, la ingobernabilidad y sus agentes violentos. La crónica y los textos de carácter testimonial publicada no sólo en los periódicos o páginas de internet sino recopiladas en antologías o libros de autor [...] enriquecen una veta 
para los lectores ávidos de "explicaciones", ávidos de comentar con otros las oblicuas sospechas de la "Verdad" (Velasco, 2013: 168).

Según el autor, el tiempo imaginario en el que transcurren las novelas es la década de 1980 y hasta principios de 1990. Sin pretender ser una denuncia es innegable que las historias "revelan la sordidez de la agresividad que enlaza la vida de vivos y muertos en la frontera norte" (Santos, 2015: 96). Varios son los espacios de la cartografía narrativa de la trilogía del desencanto: el locus urbano (Ciudad Juárez), locus desertus (El Millón, Zaragoza), el locus serrano (Casas Grandes, Madera, Parral, Namiquipa, Manzano, Creel), locus fronterizo (Río Bravo, Waterfill, Columbus, Tx., El Paso, Tx., Schulenburg, Tx.) y locus noreste (Mazatlán, Badiraguato). Toda esta geografía física por la que transitan los personajes es una "zona caliente" pues se conoce la presencia de los jefes de los carteles de la droga y el negocio que controlan en cada una de estas regiones, así como las autoridades que están coludidas con los narcotraficantes. El imaginario espacial, entonces, es una zona de desastre en el sentido que es un territorio agobiado por el clima de violencia, miseria y venganza y que contamina todo el ambiente, convirtiéndolo en una zona de grandes enfrentamientos y rivalidades por tener el control de la zona. En este cruce de fuego tiene lugar la vida de los personajes que son los protagonistas de las historias.

En cada una de las novelas ${ }^{4}$, tres son los ejes principales que hilvanan la trama central y que recaen en la fuerza protagónica de los siguientes personajes:

Corazón de Kalashnikov: Jessica, Violeta y Juanita.

El reino de las moscas: $\quad$ Ana, Esperanza y Fernanda.

Música para perros: $\quad$ El muchacho, Flor y Graciano.

En el caso de $C D K$, de las tres figuras de los bloques narrativos, dos son asesinadas brutalmente. Jessica, al inicio de la novela, por un ajuste de cuentas por error, cuando la que debía ser asesinada era Flor (Concepción Valles) y Juanita Quintero, la Grandota, la dueña del Club Paraguay, por permitir la afrenta de Flor con el patrón:

4 Para aludir a cada una de las novelas de la trilogía, se utilizarán las iniciales del título de cada una CDK, Corazón de Kaláshnikov, ERM, El reino de las moscas, MPP, Música para perros. Vale la pena señalar también que, dada la escasez de material bibliográfico de estudios especializados en torno a la obra de Páez Varela, me concentro en las entrevistas realizadas por Danilo Santos, quien ha trabajado por varios años la estética de la violencia. También en la conversación que tuve con el autor, la tesis doctoral sobre la violencia en la literatura de norte y el artículo de la Dra. Magaly Velasco, así como los artículos, reseñas y comentarios de la página del autor. 
Corazón de Kaláshnikov presenta sin tapujos desde el inicio el núcleo de su trama: la ejecución de una mujer en manos de un sicario que ni sabe a quién mata: llega, dispara, ve saltar la sangre, caer el cuerpo sin vida, y se retira de regreso a su casa, sin emoción, sin entusiasmo ni remordimientos; con sangre fría, eficacia y la satisfacción del deber cumplido. La víctima -de quien sólo sabemos el nombre: Jessica-ignora la causa de su ejecución, no conoce a su asesino y ni siquiera se da cuenta cuando muere: está viendo las noticias, suena el timbre, se levanta a abrir, mira un ramo de flores, escucha el disparo y se pierde en la nada. Así de fácil. Matar y morir en Ciudad Juárez, parece decirnos Alejandro Páez, es la cosa más banal del mundo (Parra, 2009).

En ERM, las tres figuras femeninas son víctimas, pero de diferentes circunstancias. Ana es la compañera de Liborio Labrada, un narcotraficante de gran peso en la zona fronteriza que luego es traicionado por el Comandante Refugio Cuco Ramírez que lo anda cazando. En un retén, yendo para Buenaventura, Ana no se detiene y empieza la balacera donde ella muere. Esperanza es la esposa de Víctor, un anciano dentro de los predicadores de la iglesia, que, por las creencias, no acude al servicio médico y muere por complicaciones de parto. $Y$ Fernanda Labrada, esposa de Liborio, padre del primero, muere en un accidente ferroviario calcinada y nunca se encuentra su cuerpo.

En $M P P$, el muchacho, que es una figura casi animal al principio de la novela, se nos revela más adelante que es hermano de Flor y muere de cáncer de pulmón. Igualmente se presenta a Graciano, a quien, por un descuido al intentar liberar a los animales salvajes del rancho de don Liborio, se le escapa un disparo, lo que pone en alerta al patrón que, al descubrirlo, lo mata. Finalmente, Flor (Concepción Valles) es la única que sobrevive y logra reestablecerse en el pueblo y echar andar de nuevo lo que Graciano, su esposo, había administrado con su patrimonio.

A lo largo de la trilogía, vemos que los personajes femeninos provienen de hogares destrozados y en condiciones de extrema pobreza. Se aferran a la vida y luchan por subsistir, aunque el mal que ronda los vuelve presa fácil y son víctimas de ultrajes. Esto propicia que aprendan que para subsistir a veces hay que claudicar y lo más fácil sea convertirse en victimario:

Violencia y cotidianidad. Vida y muerte. Audacia y miedo. Amor y barbarie. Binomios que dan consistencia 
[...] a la trilogía. Alejandro Páez traza la estructura en una suerte de arboreación argumental. Al dividir los libros en tres partes, Páez ubica las escenas centrales y en torno a ellas desgrana en escenas concéntricas la historia de los demás involucrados hasta conformar una espiral cuyo sustento es la atmósfera caótica. Así, los personajes ensayan [...] su danza de la muerte, dejándose envolver por la contraparte temática del relato: el amor (Parra, 2009) 5 .

La violencia se traduce entonces en la muerte, en el crimen, en la tortura, en la lucha sin cuartel, en la corrupción desmedida, en la negligencia de las autoridades por dar el carpetazo y no proceder con la investigación, la ingobernabilidad y la inestabilidad social. En el primer ejemplo de estas condiciones tenemos el brote de violencia que se desata cuando Flor se niega a satisfacer a una de las poses sexuales con el patrón y lo avienta, lo que provoca que éste caiga y se golpee. Esto desencadenará la venganza y persecución, que acabará con el asesinato de Jessica, hecho con el que inicia la novela.

Síganla. Allí va, la perra. No le hagan nada. Que no los vea. Sólo anoten su dirección para hacerle una visita. Le damos el trabajo a alguien más. Alguien de fuera porque la doña tiene muchos amigos. Ya verá esta pendeja en lo que se metió. Al patrón nadie lo toca. Ya verá también La Grandota. Esta es la última ¡Son putas, chingada madre! La doña nunca aprendió. De esta no se salvan. Ninguna de las dos se salva..." (Páez Varela, 2014: 114-115).

Juanita, apodada la Grandota en el Club, protege a Flor Valles tras la agresión que esta comete con su primer cliente, un jefe criminal peligroso. A raíz de la agresión y de la protección que brindan para esconderla, se decide la muerte de Flor, la de Juanita, y esta pasa también en la vendedora de medias, que muere por error en vez de Flor. La dueña del prostíbulo es condenada por defender a la joven mestiza de diecinueve años que acaba de llegar de un pueblo del interior (Santos, 2015).

En el siguiente ejemplo, tenemos el caso de la tortura con toda la saña, realizada por Liborio Labrada contra el muchacho que se atrevió a asaltarlo afuera de su casa cuando regresaba de un viaje. Luego nos enteramos que era Moisés, el novio de Magdalena, y que fue un plan

5 Aun y cuando Parra alude exclusivamente a la novela de Corazón de Kaláshnikov, considero que la tesis que propone se aplica al contexto argumental y temático de la trilogía del desencanto, razón por la cual la incluyo como tal en la argumentación. 
diseñado por ella. Ambos involucraron a un muchacho llamado Joaquín para que los alertara, que también es asesinado. El castigo es abominable y sirve para escarmentar a todos los que rondan por la zona y para acrecentar la fama, para que sepan quién es Liborio Labrada.

\begin{abstract}
Este se queda aquí. Si pide agua le dan un chingazo. Si quiere ir al baño, le dan un chingazo. Si pide comida, le dan un chingazo. Sólo déjenlo llorar. Se lo merece, el pobre. Llévense al muertito y tírenlo donde no lo encuentren. A éste me lo dejan aquí en custodia. Nadie tiene permiso de hablarle (Páez Varela, 2012: 84).
\end{abstract}

El tercer ejemplo es un caso de "rito de iniciación" a los sicarios. En un suceso en que unos delincuentes asaltan el rancho y le piden dinero a la vieja, que es quien ha acogido al muchacho. Éste responde de una manera astuta, sagaz e inusitada, con una habilidad en el manejo de la pistola y con tan buena puntería, que mata a los atacantes, por lo que Liborio Labrada lo invita a ir con él al siguiente trabajo que tienen que realizar.

El muchacho entró con una bolsa en una mano y en la otra, una pistola. El que estaba en el baño, el más inquieto, alcanzó a verlo. Fue el primero en caer. ¡Pum!, el primer disparo. Los otros se voltearon y así como giraron, así fueron cayendo. ¡Pum, pum!, dos tiros. El cuarto no estaba armado. Intentó decirle algo, extendiendo las manos hacia él. ¡Pum!, el último tiro (Páez Varela, 2013: 38).

\title{
¿Cuál es la identidad de estos espacios urbanos norteños, topo- tesia de una realidad nacional?
}

$\mathrm{Al}$ inicio de la trilogía, en $C D K$, la dedicatoria versa: "A Ciudad Juárez, desierto sin descanso". Esta caracterización del autor posiciona a la ciudad no sólo como locus urbano, sino como el espacio fronterizo, tránsito de desplazamientos migratorios e imaginario, con una esfera semántica cargada de varios significados: ciudad que, dada la afluencia migratoria de mexicanos que creen encontrar en la frontera una mejor calidad de vida, ha incrementado sus cinturones de miseria; ciudad que cuenta con el advenimiento de la industria maquiladora con la consecuente ola de feminicidios, con los brotes de inseguridad derivados de la presencia del cartel de Juárez, los actos delictivos que han proliferado tanto en atracos como en secuestros, los ajustes de cuentas, los actos de corrupción y la guerra contra el narcotráfico por parte del Estado. Una ciudad que además de luchar 
contra las inclemencias del tiempo, la aridez del desierto y lo extremo del clima, ahora se enfrenta a los males que la aquejan y que se han afincado en ella como una distopía total.

Alejandro Páez Varela se refiere a la trilogía como la del "desencanto" y en esto hay una mirada llena de melancolía, de un Juárez que se ha perdido, que está contaminado y devastado y que pretende resurgir de las cenizas como un ave fénix. Transitar por sus calles es ser testigo de lo que está provocando el derrumbamiento de una ciudad que es el país de en medio, un lugar de desechos, una especie de no lugar, donde el que llega tiene que enfrentar una lucha continua para sobrevivir si quiere permanecer en la ciudad. La descripción que el autor hace de esta geografía urbana se vuelve grotesca y bizarra. Es una visión desgarradora de la pobreza, la miseria humana, tanto en lo económico, como en una moral que se va desvaneciendo, pues no hay principios, credos o religión a los cuales asirse. En un mundo de consumo y bienestar, esta topotesia es el espacio simbólico de un México en su faz más caótica y aberrante. Una realidad que se quisiera ocultar pero que los hechos y las noticias que los difunden no hacen más que evidenciar que ya es imposible el ocultar.

En $C D K$ se alude a la imagen de un Juárez como un lugar de desechos y la alusión es tan fuerte porque no hace referencia solo a los desperdicios, como si fuera un basurero, sino que es una metáfora degradante que alude a esos dolientes que son sus habitantes, unos miserables sumidos en una fatalidad constante. El convivir con esta circunstancia de despojo los transfigura en seres devaluados totalmente, "se es un desecho". Hay una condición de ausencia de identidad, de no pertenecer a ningún lado, porque precisamente al estar "de este lado" implica ese reduccionismo fatalista de convertirse en un desecho. Aquí habría que recordar la famosa frase atribuida a Don Porfirio Díaz, pero cuya autoría pertenece al abogado regiomontano Nemesio García Naranjo “Pobre México, tan lejos de Dios y tan cerca de Estados Unidos!". Y eso precisamente se ve en almas atormentadas por un total abandono, y en las que existe una fe de una manera que llega casi al fanatismo, lo que también provoca la muerte como en el caso de Esperanza. La cercanía con Estados Unidos propicia la proliferación de los centros nocturnos, de la zona de tolerancia y de la distribución de la droga, ya que muchos de los militares de Fort Bliss cruzan la frontera para disfrutar de la vida nocturna en Ciudad Juárez:

Mientras anden de este lado, sin embargo, vivirán de los desechos. De todo tipo de desechos. Juárez es una ciudad de desechos. Desechos se viste, desechos se 
come: se es un desecho. Nadie dice que se vive mal: peor se está en otras partes de México. Pero vivir al sur de la frontera y al norte del país obliga a convivir con (y ser) desechos. Y así fue desde mucho antes, casi desde la firma de los tratados y hasta nuestros días; así fue desde que El Paso, apenas un barrio pasando el río, se volvió un pueblo aparte (Páez Varela, 2014: 155).

En ERM, con los personajes de Magdalena y de Moisés, se alude a la zona aledaña a Juárez, conocida como Zaragoza, que se convertirá en la topotesia de "el reino de las moscas". Un lugar de pobreza extrema, de seres que por generaciones han vivido despojados de una tierra que les pertenecía y que fueron doblegados. El tiempo ha transformado el recio carácter de estos indios insumisos y ahora son personas en duelo permanente, que no se recuperan de una pérdida, que no tienen el arraigo y en quienes persiste una añoranza eterna por el paraíso perdido.

\begin{abstract}
En Zaragoza vivían los de mayor pobreza. Vivían los despojados del Valle de Juárez, nietos de indios insumisos que todavía a principios del siglo XX cortaban cabelleras y andaban con su orgullo a caballo, pero que fueron abatidos por los ejércitos de Estados Unidos y México. ¿Quiénes vivían en Zaragoza? Personas en duelo permanente, que no aspiraban a cruzar a Texas porque no sabrían ganarse la vida allá, en donde en teoría y sólo en teoría, no se necesita más que estar dispuesta a ser esclavo (Páez Varela, 2012:. 38).
\end{abstract}

Todo el lugar es deplorable, lleno de inmundicia y, para lograr la descripción de mayor efecto, Páez Varela alude a las moscas, a esos insectos que merodean en los lugares donde la higiene y la salubridad no ocurren y cuya presencia denota ese panorama desolador; las circunstancias apremiantes en que la gente vive, con la estrechez lamentable de una penuria infinita. Como lo expresa Danilo Santos (2015), en Zaragoza el sujeto es agraviado de forma permanente, donde el determinismo y la precariedad lo caracterizan. La mujer ocupa un lugar central dentro del conglomerado de miserables que lejos están de alcanzar el sueño americano:

Zaragoza era el reino de las moscas. Sólo se iban en el instante de la tragedia; durante los diluvios o en las nevadas. Y un segundo después aparecían en cantidades groseras a reclamar lo que les pertenecía, a pararse en 
los labios de los niños y en las frentes de todos. Formaban nubes en torno a las letrinas, a las cocinas, a los gallineros y, de manera especial, junto a las marraneras (Páez Varela, 2012: 41).

En $M P P$, Flor en su segundo viaje a Juárez aprende la lección, como ella dice, y reflexiona en torno a la personalidad del locus distópico de la urbe fronteriza y la describe como una visión apocalíptica donde confluyen todos los males, "tanta mierda", pero lo peor de todo, es la degradación moral, política, económica y social que va afectando cada uno de los rincones de la ciudad. La urbe se convierte en el centro de batalla cotidiana, pues ya sea en la calle, en la rutera, en el Club Paraguay, en el Puente Internacional, en cada sitio, hay un riesgo inminente, hay un peligro al acecho pues todo se ha ido llenando de mierda. Aun así, hay atisbos de esperanza, porque en esencia, la ciudad prevalece, pues en sus entrañas hay nobleza y es lo que pretenden rescatar las historias de amor: que precisamente sea el amor el que pueda vencer tanta podredumbre y miseria social.

Juárez es un hoyo negro. A Juárez no se va a aprender porque si aprendes allí, ya te llevó la chingada. A Juárez se va a luchar, a sacar los dientes. 0 te hundes. 0 te hunden entre todos. Mire, no es que la gente sea mala. Tampoco que el aire sea malo. Es tanta mierda. Yo conocí mucha mierda, créame. Una conoce mucha mierda. Los más mierda no somos usted o yo. Los más mierdas no son los narcos ni los malandros; esos qué: son como usted y como yo, pero más listos. Los mierda, los verdaderos mierda, son los políticos, los policías. Y de esos hay siempre puños y puños. Donde quiera se aparecen. Nomás están para sacarle a uno el jugo. Nomás están para vivir de los otros. A Ciudad Juárez lo pudren los políticos porque Juárez, se lo digo de verdad, Juárez es noble. Sí, sí, como dice Juan Gabriel: Juárez es noble. Los que no son nobles, son los pinches políticos. Puta bola de vividores. Puta bola de corruptos (Páez Varela, 2013: 89-90).

Pareciera que en esta sociedad hay puros depredadores que están al acecho y que la impunidad ha salido victoriosa. Ya no se puede confiar en las autoridades porque están coludidas con los narcotraficantes e incluso llegan a venderse al mejor postor, como es el caso del comandante Cuco Ramírez, que es quien ejecuta a Liborio Labrada. 
Este es el verdadero laboratorio del mal, es lo que emponzoña a la sociedad y librarla de este veneno, es lo que en tiempos del gobierno del expresidente Felipe Calderón Hinojosa, desató la ola de violencia tan cruenta que tuvo lugar en Ciudad Juárez.

\section{¿Cuáles son los avatares que aquejan a los pobladores en un intento de subsistir en un mundo de violencia que los amenaza constantemente y los orilla a desplazamientos de diferente índole?}

Se ha mencionado que aún y cuando la trilogía del desencanto no es una narconarrativa, en el contexto urbano y serrano del imaginario en que transitan los personajes la presencia del narco es inevitable. Esto constituye un mundo de violencia y de continuos desplazamientos, dado que los sicarios tienen que estar en constante cambio de domicilio para controlar tanto la seguridad personal como el negocio de la droga. Aunado al mundo del narco, entonces, se asocia el tráfico de droga, la venta y compra de estupefacientes, el crimen organizado, los asesinatos a sueldo, las redes de prostitución y la corrupción de las autoridades que permiten que se establezca el negocio del narcotráfico sin contratiempo alguno en la zona.

En $C D K$, Mariano Giancana, llamado El Sheik, desde muy jovencito incursiona en el mercado de la droga, gracias al apogeo que, en ese entonces, a finales de los setenta, se extiende al mercado, en la vida nocturna de Ciudad Juárez, y que, paulatinamente, la irá convirtiendo en centro de perdición, en el prostíbulo de los "paseños", los americanos que cruzan el puente para disfrutar de mujeres, licor y droga a precio mucho más barato que en territorio norteamericano. Esta vida fácil, engancha a Mariano Giancana, lo lleva al terreno de la prostitución y después lo contactará con los grandes jefes, hasta llegar a trabajar con uno de ellos, El Chiquito:

Cientos de muchachillos como él vendían coca. Así era en esos años. El mercado era grande y próspero: los finales de los setenta y principios de los ochenta llenaron las discotecas y las cantinas con miles de juarenses y paseños -sobre todo soldados del Fort Blissdispuestos a comerse la noche. Y para comérsela, el mejor sazón era con coca. Se vendía buena y barata en las esquinas de la muy turística avenida Juárez o casi cualquiera de los barrios de la ciudad (Páez Varela, 2014: 62-163). 
En $E R M$, la vida de Liborio y Ana Labrada transcurre en un continuo desasosiego. Siempre alertas ante cualquier amenaza, ante la constante persecución del comandante Cuco Ramírez que los ha traicionado. Se guarecen en distintas partes donde tienen propiedades, como la casa en El Paso, Texas, en su Rancho, en una casa de seguridad en Ciudad Juárez, y no permanecen por varios días en el mismo lugar. Tienen el poder y el control, la riqueza y el dinero, pero no la libertad. Pueden matar y ajusticiar a quien no respeta su ley, pero también son la presa de la "justicia". La ironía de la vida hace que la muerte los atrape a los dos. Primero, cuando la policía llega a su casa, por negligencia de Ana que quiere esperar al veterinario que va a llegar con los cachorros, logran escapar. Pero luego, tienen que separarse y Ana no hace un alto en un retén y al acelerar el auto la acribillan. Por otro lado, a Liborio, lo atrapan finalmente, en una casa de seguridad y aún y cuando logra amagar al comandante Ramírez, cuando le ofrecen dejarlo con vida si lo libera, al hacerlo, lo hieren de muerte. La versión de Ana, su compañera sentimental, cuya vida muestra la zozobra constante que padecían:

Cuando llegamos a Mazatlán teníamos meses huyendo por la sierra de Chihuahua. Habían matado a un jefe en Juárez, a El Chiquito. Eso desató la guerra entre dos grupos de Sinaloa. Los de Badiraguato querían que Liborio se quedara a cargo; los de Navolato se volvieron enemigos y compraron al comandante Ramírez con un chingo de dinero. Pinche Ramírez corrupto; nos dio la espalda y hasta se quedó con la cada de El Paso, dicen (Páez Varela, 2012: 91-92).

En MPP, Flor (Concepción Valles) siente la necesidad de regresar a Ciudad Juárez en un asunto de cuentas personal. Su matrimonio con Gamaliel, quien prefiere que le llamen Graciano, le complace los primeros meses, pero siente que hay un pendiente que tiene que resolver. En este sentido, es interesante el planteamiento que el autor logra en estos personajes, pues también se da una especie de anagnórisis, una revelación del yo, sobre todo en Flor, quien en reiteradas ocasiones ha manifestado una especie de declaración de identidad. Se reincorpora en el Club Paraguay, pero nota que las cosas han cambiado, ya no es lo mismo, y la insatisfacción la lleva a la bebida y a la deriva. En una revisión médica, el doctor le sugiere que se cuide por su estado, y es ahí cuando se da cuenta de su embarazo. Renuncia al Club Paraguay y se refugia en los miserables cuartos donde vive, racionando la alimentación para lograr subsistir. Los hechos que acontecen fuera de su cuchitril serán un 
detonador importante que le harán tomar una decisión importante en el rumbo de su vida:

-iQué bueno que vino! - respondió la otra y le contó, de botepronto y asumiendo que a eso había ido, que los vecinos pensaban que la vecina no había sido asesinada por su esposo.

-No fue él. Muy por el contrario...-- agregó, usando palabras sofisticadas que seguramente había leído en el diario vespertino o había escuchado en los noticieros.

-¡Imagínese! - dijo Flor, aunque no supo por qué.

-Sí- respondió la vecina -. Ya le echaron la culpa de las otras muertas. Muy por el contrario, no fue él.

- ¿Otras muertas?

-No lejos de aquí. Varias muertas. Que las violan y las matan. Son como diez o veinte. Nadie sabe...

Flor supo que había llegado el momento de empacarDe golpe recapacitó: su aventura en Ciudad Juárez había llegado demasiado lejos (Páez Varela, 2013: 124).

Aquí ya hay una alusión directa a los feminicidios. Previamente, los asesinatos de Jessica y de Juanita se habían presentado como aparentemente aislados (no hay que olvidar que Juanita Quintero era el caso 250, pero se le había pretendido dar carpetazo) y ahora el narrador hace alusión a la recurrencia de las mujeres asesinadas como un hecho que dará a conocer finalmente los feminicidios que habían empezado a ocurrir en ese "desierto sin descanso".

\section{¿Es posible repensar el norte como un espacio privilegiado de significación geopolítica que desborda los imaginarios del narco, la inmigración, el feminicidio y la precariedad de las ciudades y comunidades norteñas?}

En la trilogía del desencanto, Alejandro Páez Varela nos ha llevado por las narrativas del dolor de personajes que han padecido los estragos de la violencia de un mundo caótico y complejo. En un locus urbano distópico y apocalíptico como lo es Ciudad Juárez, lo único que resulta posible para dar sentido al narrar tanto dolor y muerte, es el amor que prevalece y que estuvo presente aún y cuando haya sido derrotado. Es la única vía para mantener viva la esperanza de 
que la ciudad puede rescatar su nobleza y recuperarla. Por ello quizá, la novela se convierte en un espacio de reflexión, en una forma de explorar la condición humana en todos sus matices, para lo cual es menester, ver tanto el ascenso como la caída del hombre. Páez Varela me comentaba:

Es una novela de reconstrucción de valores primero para mí. Ratifica valores, los vuelve a ubicar. Muchos valores que yo tenía sobre esa sociedad, yo los volví a encontrar. Escribir para mí fue un ejercicio de encontrar en esos personajes, condiciones humanas que valen la pena ser narradas, que valen la pena que el hombre se salve por el hombre (Torres Torija, 2015).

En la melancolía y en la nostalgia encuentra el rescate de esos valores que considera importante resarcir como instrumento de salvación para una sociedad en un periodo doloroso que transita por una crisis agobiada por la violencia. El elemento antagónico está entonces fuera de la ciudad, no en la ciudad misma, por eso hay que tener esperanza en ella. De ahí que Flor afirme que Juárez es noble pero lo que está sucediendo con las autoridades es lo que la está emponzoñando, llenando de mierda.

La presencia de reminiscencias bíblicas o del tinte religioso, en algunos pasajes, hace pensar en una lectura de México, en particular del norte, como un paraíso perdido, como una Sodoma y Gomorra que purga sus pecados y vive su penitencia. Un mundo narrado que constituye ese espacio de perdición del hombre sumido en el pecado, abandonado por Dios, sin oportunidad de redención y salvación alguna. Esta sería una lectura desde una perspectiva católica, pero habría que considerar que, en muchos de los personajes, no hay conciencia de pecado, no hay conciencia del mal, por lo tanto, no son pecadores, ni penitentes, en todo caso víctimas de una serie de circunstancias que los ha orillado a asumir un tipo de comportamiento, a volverse sicarios. El caso de Magdalena es muy ilustrativo, cuando ha sido formada en apego estricto a la religión y es muy mojigata en su forma de vestir y de actuar y de pronto le dice a Ana Labrada: "Quiero matar, quiero ser como ustedes". El medio la envuelve y la atrapa. Tan es así, que trama el robo del dinero, asalto fallido donde es capturado y torturado Moisés, que, después de las condiciones deplorables en que lo liberan, fallece. Aun así, la presencia de pasajes bíblicos le da un tono de premonición, y de que la vida tiene un sentido pese a la tragedia. A esto, refiere el autor: 


\begin{abstract}
Son novelas protestantes. Yo pensé que eran novelas de esperanza, veía en la composición, volvía a ver hacia las mujeres, donde la vida, el amor, los hijos importan; se viven con las tragedias, ni modo. Que el amor importa, y ahí adentro el baño de esos pequeños hilos de oro de los versículos de la Biblia para tejer las novelas. En medio de todo, la referencia a la Biblia es un oasis, se presenta más como el libro de oro, no es un panorama apocalíptico (Torres Torija, 2015).
\end{abstract}

A lo largo de la trilogía del desencanto, el lector transita por diferentes estadios que exploran la condición humana: del amor al desamor, de la venganza al perdón y de la reivindicación humana a través de la gracia. En $C D K$ el amor prevalece sobre todas las cosas: Jessica que se enamora de Amado, Amado-Johnny que se enamora de Rose, Mariano Giancana, El Sheik, que se enamora de Violeta. En ERM, la venganza es el leitmotiv con mayor fuerza, sobre todo en la figura del narcotraficante Liborio Labrada que vengará la muerte de Ana, torturará a Moisés y matará a Jacinto, y aún muerto, perseguirá a Cuco Ramírez quien lo traicionó. Eulalio Labrada se vuelve loco con la obsesión de buscar el tesoro enterrado por Fernanda Labrada y Refugio Ramírez que fallecieron en el accidente ferroviario y que luego cree que los familiares se lo robaron. Magdalena sufre por haber pensado el robo que terminó con la muerte de Moisés y trata de buscar el consuelo. Finalmente, en $M P P$, Flor es el personaje que irá uniendo los cabos. Su hermano, el muchacho, logra cobijo en el rancho de Liborio Labrada gracias a la vieja que cuida la cocina, quien le da asilo y lo asiste. Permanece en el rancho hasta su muerte, por una

enfermedad letal y con las ganas de matar a Liborio Labrada, a quien odia. Gamaliel (Graciano), su esposo, por unos meses le brinda una felicidad que la complace temporalmente pues ella siente que tiene que regresar a cerrar ciclos a Ciudad Juárez. La ola de violencia y su embarazo la hacen regresar y ahí José Crisanto le da la noticia de la muerte de su esposo, de su hermano, el muchacho, y el paradero de sus otros hermanos. Finalmente, ella logra emprender una etapa nueva con su hija Flor Valles, enfrentando las adversidades y con el valor de tener la fortaleza para lograrlo.

\title{
¿Cuáles son los mecanismos literarios utilizados para recrear una "narrativa del dolor"?
}

En el plano escritural, se percibe una expresión diáfana y certera, sin alambiques, pero sí con minucioso cuidado de mantener el aliento del poder evocador de la palabra. Hay muchos ecos de García Már- 
quez en las formas enunciativas y en cuanto a la composición; un vaivén que toma y deja, vuelve a contar y a plasmar la historia. Afirma Páez Varela: "Hay algo de las técnicas de la crónica y el reportaje, pero la definición era hacer una novela de amor. Un libro amargo, triste". (Torres Torija, 2015). La trilogía se convierte en un caleidoscopio narrativo afincada en una estructura compositiva de tres ejes soportados a su vez por siete bloques narrativos en cada novela. Las historias y las novelas van construyendo vasos comunicantes de manera que, aún y cuando pueden leerse de manera independiente, al final tenemos un solo fresco de la cartografía literaria del locus fronterizo. Cada uno de los episodios narrativos contiene lo que pudiera considerarse pequeñas viñetas que van construyendo la historia de cada uno de los personajes centrales en cada eje $y$, a su vez, se van dando elementos secundarios que permiten construir elementos de enlace con las otras historias.

La cartografía narrativa por la que Páez Varela ubica a sus personajes es prioritariamente la zona serrana y la zona fronteriza. Cada uno de los poblados y el locus urbano se transfigura en el territorio de la muerte, en la topotesia, en una geopoética de la violencia derivada de las implicaciones de la presencia del narcotráfico en ambos lugares. Por la manera en que son descritos cada uno de estos sitios en los ejemplos anteriores, y por la gran carga metafórica, se puede afirmar que el autor logra plasmar una geopoética del paisaje chihuahuense, la otra faz bondadosa de la naturaleza y de la imagen poética con la cual es descrito el locus urbano.

Páez Varela explora en la crónica una escritura que amalgama los relatos orales con los hechos históricos y esto le permite fabular a partir de los imaginarios. Hay una riqueza en los registros, en las posibilidades expresivas, como cuando alude a las formas muy particulares de hablar de la gente según su lugar de origen. Estos elementos que podemos calificar de costumbristas le dan colorido y frescura a una narrativa del dolor que requiere de un paliativo discursivo para suavizar el tono de la narración. No hay que olvidar que la apreciación del autor, respecto a su ciudad de origen, es que "Juárez es una ciudad reducida a las cenizas (en términos morales), una ciudad de progreso, pero definitivamente destruida" (Torres Torija, 2015).

La cartografía de la violencia en la trilogía del desencanto de Alejandro Páez Varela nos presenta un desfile por el cual transitan "narcos, policías, periodistas, prostitutas, malvivientes, mariguaneros de barrio, muleros, parqueros, migrantes, indígenas, políticos, sicarios, comerciantes, víctimas o victimarios, todos desfilan por las páginas hasta configurar el rostro oscuro, subterráneo, de la urbe en los últimos años del siglo" (Parra, 2009). Este mundo bizarro, grotesco y 
alucinante muestra la terrible realidad a la que ha sido expuesta Ciudad Juárez a partir de la ola de violencia que se desató por negligencia gubernamental o por excesiva tolerancia e impunidad.

Páez Varela ofrece esa mirada aguda a una realidad que no podemos dejar de contemplar por más que sea una verdad incómoda. No deja de ser verdad, y como tal, tenemos que encararla para construir un mejor futuro y enmendar este agobiante presente que sigue dando muestras de una violencia que todavía cobra vidas, que continúan las víctimas, la impunidad, la corrupción, la ingobernabilidad. ¿Será en verdad que ya hemos perdido el rumbo y no hay posibilidad de recuperar el paraíso perdido? El lema del escudo de Chihuahua dice que su gente es valiente, noble y leal. Habrá que hacer honor a esos atributos para rescatar el clima de paz que tanto se añora en estas tierras.

\section{Bibliografía}

Aguilar Sosa, Y. (2009). Por culpa de una ametralladora no pudo ser Corín Tellado. El Universal. Domingo 6 de septiembre. P. 17.

De Orduña Fernández, E. (2017). Estética y violencia en la literatura del norte de México. (Tesis doctoral) Universidad Autónoma de Madrid. Recuperada de: https://repositorio.uam.es/handle/10486/681244

Páez Varela, A. (2009). Mis libros. Alejandropaez.net. Recuperado de: http://www.alejandropaez.net/mis-libros/ . (2012). El reino de las moscas. México: Alfaguara. . (2013). Música para perros. México: Alfaguara. . (2014). Corazón de Kaláshnikov. (1a. ed.) México: Alfaguara.

Parra, E. A. (2009). La estructura del caos. Alejandropaez.net. Recuperado de: www.alejandropaez.net/12-11-2009/eduardo-antonio-parra-escribe-sobre-corazon-de-kalashnikov

Santos López, D. (2015). Los territorios de la violencia en la novela policial y la narcoliteratura. Aisthesis, (58), pp. 81-109.

Santos López, D, A. Vásquez, I. Urgelles (2016). Yo digo que escribo historias de amor y me salen un montón de balazos. Entrevista a Alejandro Páez Varela. Mitologías hoy. Revista de pensamiento, crítica y estudios literarios latinoamericanos. Vol. 14. Diciembre pp. 305-313. 
Torres Torija, M. (2015). Entrevista a Alejandro Páez Valera. Inédito. Café Padam. Col. Roma Norte. Ciudad de México. 14 de noviembre de 2015.

Velasco Vargas, M. (2013). Periodismo narrativo y novela en Ciudad Juárez: Alejandro Páez Varela y su reino de moscas. Polifonía, III (I), pp. 167-177. 